\title{
La voz, el murmullo y el silencio. De nuevo sobre la lectura silenciosa
}

\section{Sergio Pérez Cortés}

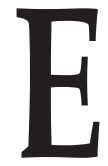

n la historia de la comunicación escrita la expansión de la lectura en silencio tiene una importancia particular: su presencia ha llegado a ser tan masiva que todos nuestros lectores modernos, especialmente los más cultivados, leen esencialmente en silencio y sin mover los labios. Esta práctica millones de veces repetida ha otorgado rango de evidencia a dos cuestiones: que hay una fusión natural entre soledad, recogimiento y lectura, y que la lectura es un proceso enteramente mental. La imagen inmediata que se nos ofrece es que la lectura es el modo de comunicación establecido entre un texto escrito definitivo y un lector silencioso. Resulta entonces difícil percibir el lento proceso por el cual el reconocimiento de los signos visuales contenidos en la página se realiza exclusivamente por el ojo, mientras el cuerpo se esfuerza en evitar el movimiento rítmico, la vocalización y la subvocalización del texto:

[...] para muchos de nosotros, la imagen ingenua de la lectura es virtualmente el de la operación de una máquina computadora y decodificadora: el cerebro es el procesador que de manera simultánea recoge y traduce el "código" de la página impresa, en un tipo de información que el cerebro puede interpretar. ${ }^{1}$

Quisiéramos sustentar aquí que esta práctica de la lectura es resultado de una trama de factores que a su vez indican profundas transformaciones sociales y culturales. Aunque es una adaptación "intelectual" de la mayor importancia, porque individualizó e interiorizó la experiencia de la lectura, en ella se refleja una serie de exigencias que van mas allá del individuo: la ne-

${ }^{1}$ W. A. Graham, Beyond the Written Word. Cambridge, Cambridge University Press, 1993, p. 32. 
cesidad de leer con mayor velocidad una masa creciente de información disponible y fácilmente accesible; la necesidad de consultar y asimilar un conjunto de libros especializados, técnicos, científicos y lógicos, de una gran complejidad; la necesidad de comprender enunciados originales, nunca antes escuchados; la necesidad de socializar la lectura de comprensión, etcétera. La lectura silenciosa se encuentra así en la intersección de exigencias y motivaciones intelectuales que son propias de la cultura contemporánea. Quizá logremos revelar lo específico de esta práctica al compararla con estrategias de lectura que movilizan recursos $y$ persiguen fines diferentes a los nuestros; puesto que es "en silencio", sus opuestos son la lectura en voz alta y la subvocalización. Veamos pues más de cerca su genealogía y sus peripecias.

Las diversas estrategias de lectura no son excluyentes entre sí y han coexistido durante largos periodos históricos. Esta presencia simultánea no impide que cada una de esas prácticas haya ejercido un predominio cultural en diferentes momentos, porque al poner en juego un sistema de premisas y objetivos, cada una de ellas recibe una mayor o menor valoración social. Así, la antigüedad griega y romana conoce la lectura en silencio pero circunscribe su práctica a círculos reducidos y a individuos aislados. Aristóteles y Nerón, en cierto modo tan opuestos, forman parte de ese pequeño grupo. La Edad Media conoce también la presencia simultánea de varias estrategias de lectura, pero comparte con la antigüedad la valoración de la palabra humana y por tanto el predominio de la lectura vocalizada:

[...] es posible distinguir tres técnicas de lectura que durante la Edad Media fueron ampliamente difundidas y concientemente utilizadas para propósitos diversos: lectura en silencio; lectura en voz baja, llamada "murmullo" o "rumiación" que ayudaba a la meditación y servía como herramienta para la memorización, y por último lectura vocalizada que, como en la antigüedad, demandaba una técnica particular y era similar a la práctica de la recitación litúrgica o canto. ${ }^{2}$

En un proceso gradual que se inició en los siglos VIII y IX, esa competencia específica que es la lectura en silencio desbordó los scriptora monásticos, alcanzó al mundo universitario de la escolástica entre los siglos XII y XIII y se instaló paulatinamente entre las aristocracias laicas a partir de la segunda mitad del siglo XIV. ${ }^{3}$

Cada una de estas prácticas de lectura es un índice de la relación cambiante

${ }^{2}$ A. Petrucci, citado en H. J. Martin, The History and Power of Writing. Chicago, University of Chicago Press, 1994, p. 68.

${ }^{3}$ Cf. Roger Chartier, El mundo como representación. Barcelona, Gedisa, 1992, p. 137. 
que une un lector y un texto. Tal relación nunca ha sido la misma porque la lectura, además de un problema técnico, es una forma de re-producir el significado de un escrito y de establecer un vínculo con la comunidad de otros lectores y con determinadas tradiciones de lectura. Por las habilidades que moviliza en primer lugar: hay una gran diferencia entre el lector experimentado y el lector menos hábil que está obligado a oralizar lo que lee -y por tanto a recurrir a ciertas formas textuales y tipográficas-, para poder comprenderlo. Por la motivación en segundo lugar: se lee con una sed ardiente para alcanzar el cielo, para comprender a la naturaleza o a los hombres, para mejorar nuestra vida moral, o bien se lee con circunspección "eventualmente para reparar nuestros radios". ${ }^{4}$ Además, por la modalidad que se adopta, la lectura puede ser sacralizada, laica o narcisista, pública o privada, virtuosa o rudimentaria, etcétera. Finalmente, por los escritos disponibles la lectura puede ser "intensiva", es decir, pocos libros leídos con el propósito de ser memorizados, o "extensiva", es decir, ante una diversidad de textos, géneros o dominios de aplicación. La relación silenciosa de un lector a su texto se explica, lo mismo que las demás, por el juego de las valoraciones que han surgido o se han eclipsado, las actitudes que se subrayan o se cancelan, las motivaciones que irrumpen o se mitigan.

El encuentro de un lector con un texto se presenta primeramente como un problema técnico. La razón es que, en la historia, el escrito se ha venido ofreciendo a la mirada bajo formatos siempre cambiantes; y esto es significativo, porque la lectura comienza por un acto de reconocimiento cuyo fin es asociar una serie de elementos gráficos convencionales con una serie de elementos fonéticos que poseen valor lingüístico en la cadena del habla. Coincidimos con E. Havelock en reservar el nombre de "lectura" al reconocimiento unívoco de esos signos gráficos, simplemente para distinguirla de procesos que requieren de una mayor preparación previa, como el desciframiento, la decodificación o la interpretación a las que obligan otros sistemas de escritura. Aunque cada una de las dificultades técnicas provenientes del sistema gráfico tiene un efecto particular sobre el proceso de lectura, en Occidente, después de la aparición del alfabeto, la más importante de ellas se refiere al sistema de puntuación y en particular a la ausencia de separación entre palabras. La llamada escritura continua asociada con la irregularidad o ausencia de puntuación son causas suficientes para obligar al lector a vocalizar el texto que tiene frente a sí, porque dificultan enormemente al ojo la tarea de reconocer los elementos lingüísticos con significado como palabras, sintagmas o frases. El oído es entonces llamado en auxilio de la vista porque está mejor preparado para ese reconocimiento dentro del flujo del habla humana. A la inversa, si la

${ }^{4}$ Robert Darnton, "Los lectores le responden a Rousseau: la creación de la sensibilidad romántica", en La gran matanza de gatos y otros episodios. México, FCE, 1994, p. 254. 
grafía permite un acceso directo al significado de la palabra, como en el caso de la preposición "a" en oposición al tiempo verbal "ha", o como en el caso de los ideogramas chinos, la habilidad de la lectura en silencio se ve incrementada, por eso un lector chino experimentado posee una competencia mayor en la lectura silenciosa que su símil en Occidente. ${ }^{5}$

De manera general puede decirse que a medida que el sistema gráfico reduce la necesidad de una manipulación fonética previa al reconocimiento lexical posibilita la aparición temprana de la lectura silenciosa, mientras que por el contrario, a medida que el sistema de escritura impone una mayor manipulación fonética antes de lograr reconstruir la palabra, la necesidad de la vocalización y el recurso a la memoria se hacen más imperativos. Es posible sin duda evitar la verbalización del texto, pero se requiere un largo periodo de entrenamiento para lograrlo.

Aún cuando la representación de cualquier lengua puede hacerse mediante sistemas gráficos diversos, puede afirmarse que el alfabeto es una mejor adaptación a las lenguas cuyas características morfológicas son el ser polisilábicas y flexionales, como es el caso del grupo indoeuropeo. La escritura continua es una característica propia de estos sistemas de escritura alfabéticos. Esto se explica porqué hasta antes que el alfabeto marcara gráficamente las vocales, cualquier texto transcrito en sistemas ideográficos o silábicos sin vocalización debía contener algún tipo de separación entre palabras, sea con espacios o con puntos, porque sin ésta se introduce un grado intolerable de ambigüedad; un sistema semejante ofrecería la representación $\mathrm{t}$ t $\mathrm{t}$ p z de la cual habría que derivar el original griego "atalotata paizei" (... con mayor gracia), que son las dos últimas palabras del llamado Hexámetro de Dipilón, primer ejemplo conocido de uso del alfabeto griego. ${ }^{6}$ Por supuesto, esta dificultad técnica no implica la absoluta imposibilidad de leer la frase en cuestión, pero al precio de un considerable trabajo previo:

[...] esas lenguas escritas podían haber sido descifrables, dadas determinadas convenciones para la sintaxis, reglas gramaticales bien definidas, convenciones sobre el orden de las palabras e indicios contextuales, pero sólo tras una intensa actividad cognitiva previa al acceso léxico; tan intensa como para tornar impracticable la lectura según la conocemos. $^{7}$

${ }^{5} C f$. P. Saenger, "La separación de las palabras y la fisiología de la lectura", en D. Olson y N. Torrance, eds., Cultura escrita y oralidad. Barcelona, Gedisa, 1995.

${ }^{6} \mathrm{Cf}$. K. Koob, Literacy and Paideia in Ancient Greece. Oxford, Oxford University Press, 1994, p. 271. 
La puntuación representa una dificultad adicional. Ni los griegos, ni los latinos, ni la primera civilización medieval fueron capaces de fijar un sistema estable de puntuación, cuyas primeras manifestaciones habrán de aparecer en el mundo carolingio y que sólo podrá hacerse definitivo en la cultura impresa. Algunas de las deficiencias de la antigüedad son muy notables: carecían de signos de interrogación o de exclamación y aunque podían marcar el final de una estrofa mediante el guión (el paragraphos), éste podía utilizarse también para señalar el final de una frase. El final de frase podía, además, ser marcado mediante un espacio o un punto. Pero para este último se adoptaron diversas posiciones, más alto o más bajo respecto a la línea inferior del texto, que podían significar a su vez pausas más o menos breves en la lectura: "Nicanor, en tiempos de Adriano, usó no menos de siete posiciones del punto, así como otro signo (hypodiástole) equivante a nuestra coma, por lo que se ganó el sobrenombre del 'puntuoso' (stigmatias)". 8

Es poco probable que los textos griegos clásicos hubiesen poseído algún tipo de acentuación. No es sino en el mundo romano que aparecen, aún de manera asistemática, una serie de signos prosódicos destinados a marcar la cantidad y la aspiración: tres acentos, grave ('), agudo $\left(^{(}\right)$, circunflejo $\left(^{\wedge}\right)$; dos cantidades: breve $\left(^{(}\right)$y larga $\left(^{-}\right.$); la aspiración ( ${ }^{-}$) y la no aspiración ( I ). Lo más significativo de estos signos prosódicos es sin embargo que parecen orientados en un sentido distinto a la idea moderna de notación que es aportar claridad, retirar ambigüedades, establecer asociaciones lógicas. Por el contrario, los signos prosódicos romanos están destinados a apoyar la vocalización del texto, a guiar a la voz, ayudando a hacer el énfasis correcto en la lectura de acuerdo con el género literario. Ellos son ante todo una preparación a la lectura y se asemejan "a la anotación de la partitura musical antes de la interpretación". ${ }^{9}$ Por eso ellos pueden ofrecer indicaciones sintácticas, semánticas, expresivas y aún juicios de valor estético o de autenticidad. Su presencia se explica pues fundamentalmente porque el objetivo de la lectura en la antigüedad es la expresión (o la dramatización, como preferían llamarla los griegos).

El mundo clásico encontraba la esencia de la lectura en voz alta en la expresión, en la capacidad de entrar en el espíritu de lo que se lee. El aprendizaje básico de la lectura, que sólo se lograba mediante la demostración personal del maestro, consistía en comprender "cómo había que pronunciar las narraciones, cómo había que dirigir los consejos con autoridad, cómo la vehemencia

${ }^{7}$ P. Saenger, "La separación de las palabras y la fisiología de la lectura", en op. cit., p. 275 .

${ }^{8}$ S. F. Bonner, La educación en la Roma antigua. Barcelona, Herder, 1984, p. 292.

${ }^{9}$ Françoise Desbordes, Concepciones sobre la escritura en la antigüedad romana. Barcelona, Gedisa, 1995, p. 230. 
rápida debía reflejar la rabia fogosa, cómo adaptar el tono cuando se imploraba piedad". ${ }^{10}$ Eso explica que además del maestro se pudiera recurrir a un actor profesional de comedias con el riesgo, según Quintiliano, de que el alumno acabe por extralimitarse en la expresión facial y en los gestos y busque imitar la voz de la mujer o reproducir el tono vacilante de los ancianos. El lugar que ocupa la serie de signos prosódicos y de puntuación se sitúa entonces en la manipulación del texto que precede a la lectura. Porque la lectura no era un acto que se iniciaba sin más ni más; ella era una tarea preparada, organizada y anotada: en clase por el maestro que "demostraba" el texto (de ahí su nombre de praelectio o lectura preliminar), antes de que cada alumno se dispusiera a leer; en la vida adulta por el gramático que a través del análisis devolvía la voz a esos textos. La lectura instantánea de un texto desconocido era, por decir lo menos, una tarea difícil:

[...] el lector antiguo se encuentra ante un texto que para él está vivo; además, si bien son muy pocos los que leen, el lector es un hombre instruido, cultivado; por último, descifrar el texto es con frecuencia la tarea de un especialista, el esclavo anagtostes que prepara con tiempo su lectura; ésta supone pues una participación activa del espíritu. ${ }^{11}$

A la serie de signos de puntuación se le encargó la tarea inmensa y difícil de convertirse en un sistema minucioso de instrucciones de lectura que debía representar gráficamente la elevación de la voz, el énfasis en ciertos pasajes, las pausas sin respiración y las respiraciones sin pausa:

[...] el ritmo de la lengua oral puede tener una función lingüística como precisar la organización sintáctica de la enunciación, una función puramente fisiológica como el respirar o una función expresiva de matices infinitos. De todas las variables del habla individual, es ésta la que se presta menos a un análisis en unidades distintivas [...] En consecuencia, es sólo parcialmente susceptible de ser escrita. ${ }^{12}$

Si se adicionan las dificultades inherentes a la escritura continua y la falta de sistematización de los signos de puntuación se percibe que la lectura era un esfuerzo intelectual y físico considerable que involucraba a la memoria, la voz, la actitud corporal, el movimiento rítmico del cuerpo: "no olvidemos que el lector romano es un 'muscular'. Le complacen los gestos amplios". ${ }^{13}$ Por eso los

${ }^{10}$ S. F. Bonner, op. cit., p. 296.

${ }^{11}$ Andrien, citado en F. Desbordes, op. cit., p. 226.

${ }^{12}$ F. Desbordes, op. cit., p. 236. 
médicos romanos recomendaban a sus pacientes leer, lo mismo que sugerían caminar o correr. ${ }^{14}$ Era, además, un acto lento porque el formato gráfico exigía constantes operaciones visuales, hacia atrás y hacia adelante, para asegurarse del reconocimiento fonético de sílabas, palabras y frases. Utilizada como un auxiliar, la actividad oral ayudaba al lector a retener en la memoria de corto plazo el fragmento de la palabra o frase que ya había sido decodificada, mientras la tarea de comprender el sentido completo proseguía a través de la decodificación visual y auditiva.

Estas condiciones técnicas hacen prácticamente inevitable la vocalización del texto. Sin embargo, al llamarlas "dificultades" ya cometemos una violencia porque no fueron percibidas como tales por los antiguos; su persistencia durante siglos obedece a otras razones objetivas. Es notable que si el mundo clásico logró que su sistema de escritura reprodujera con gran fidelidad el discurso hablado, en cambio no lo hizo coexistir con la separación de palabras, y esto a pesar de que en la antigua tradición romana, al menos hasta el siglo II a. C., las palabras eran separadas por un espacio o por un punto, tradición que se fue perdiendo gradualmente hasta adoptar la grafía "griega" que carecía de ella. La explicación de esa persistencia se encuentra sin duda en la valoración social de la lectura vocalizada, en los hábitos de lectura y en las condiciones sociales e intelectuales en las que la escritura y la lectura tenían lugar. Ante todo, porque la lectura en voz alta, ejercida sobre un número limitado de textos intensamente estudiados, encajaba en un mundo en el que la expresión oral y retórica era altamente valorizada como fuente de prestigio y de poder. ${ }^{15}$ Es verdad que la lectura era sólo una de las premisas de la retórica, pero era signo de un alto valor personal, al grado que Quintiliano al recordar a su pequeño hijo malogrado, rememora "una voz agradable y clara, una dulzura en el habla y una perfecta corrección en la pronunciación de cada una de las letras griegas y latinas..." 16 Además de una necesidad y una fuente de prestigio, la lectura vocalizada es un placer colectivo: el deleite del texto hablado, en algunos casos acompañado con una melodía, pero siempre con un involucramiento corporal, hace de la lectura un ejercicio y un compromiso psicológico completo y pleno. Considérese adicionalmente que no existía la motivación de leer un gran número de textos especializados o técnicos; no existía incluso la necesidad de una herramienta de consulta, por eso el diccionario fue desconocido en la antigüedad clásica. Tampoco se hacía sentir la presión

${ }^{13}$ R. Marichal, "La escritura latina y la civilización occidental del siglo I al siglo XVI", en M. Cohen, ed., La escritura y la psicología de los pueblos, México, Siglo XXI, 1 9 7 1 p. 215.

${ }^{14} \mathrm{Cf}$. H. J. Martin, The History and Power of Writing, p. 70.

${ }^{15}$ Cf. P. Brown, Power and Persuasion in Late Antiquity. Wisconsin, 1992.

${ }^{16}$ Citado en S. F. Bonner, op. cit., p. 297. 
de hacer de la lectura una práctica generalizada entre la población; es probable que la gran mayoría de lectores, incluso los más experimentados, estuviesen más cerca de la "alfabetización fonética" (que consiste en la aptitud de descifrar los textos sílaba por sílaba, oralizándolos y memorizándolos) que de la "alfabetización de comprensión" (que consiste en la capacidad de descifrar un texto en silencio, palabra por palabra, comprendiéndolo plenamente en el momento mismo del desciframiento). ${ }^{17}$ Por último, la idea de un lector solitario, que debía encontrar en sí mismo la fuente de la motivación a la lectura, era prácticamente desconocida

para la mentalidad elitista de la antigüedad.

En la valoración de la retórica y de la voz humana, en el disfrute estético, en la satisfacción de la memoria y en la falta de incentivos para socializar una lectura individualizada y rápida, es donde se encuentran las causas de la persistencia de la lectura en voz alta. Prácticamente todas aquellas ventajas que la lectura silenciosa ofrece a la cultura contemporánea eran inútiles en la cultura antigua, no representaban motivación alguna y por el contrario iban a contracorriente del prestigio de la palabra hablada. La lectura en voz alta no es la forma primitiva de la lectura silenciosa sino una adaptación intelectual específica que constituye una cierta comunidad de lectores y escuchas y una determinada relación entre el lector y el texto. La ausencia de separación entre palabras y de signos de puntuación sistemáticos son cuestiones técnicas pero indicativas de una relación particular entre el lector y el escrito, entre el lector y su comunidad y de esa comunidad respecto a una escala de valores. Por eso la remoción de esos elementos técnicos iba aparejada con la transformación de todo un conjunto de valores sociales y culturales.

Mientras aquellos factores prevalecieron, la valoración de la lectura vocalizada perduró también. Durante todo ese lapso la forma de transmisión del mensaje escrito requirió la colaboración entre el ojo y el oído, cómplices inseparables en esa tecnología de comunicación. El oído y la vista podrían participar en grados diversos, pero el predominio recayó en la oralización del texto, sin que ello signifique el desconocimiento absoluto de la lectura silenciosa. Un ejemplo de esta situación, citado con frecuencia son las visitas que san Agustín hacía a san Ambrosio en el momento de su pasaje por Milán: "muchas veces me hallaba yo presente en su lección [...] y siempre lo vi leer silenciosamente y como decimos 'para sí', nunca de otro modo". ${ }^{18}$ Agustín se muestra sin duda sorprendido. No tanto por el hecho de la lectura en silencio que no parece serle desconocida, sino porque estima necesario encontrar las razones que impulsan a ese hombre a actuar de ese modo. Entonces enumera:

${ }^{17} C f$. P. Saenger, "Prier de bouche et prier de coeur", en R. Chartier, ed., Les usages de l'imprimé. París, Fayard, 1987, p. 193. 
lo hace porque desea recluirse en sí mismo y no desea ser importunado en ese retiro interior; o bien, lo hace porque no desea verse obligado a ofrecer explicaciones a alguien presente que no dejaría de plantear preguntas acerca de algún pasaje oscuro y que quizá hasta se sentiría con el derecho a disputar acerca de esas cuestiones; san Ambrosio lee en silencio para evadir las obligaciones intelectuales que le impone la lectura oralizada. En busca de razones, Agustín llega a una extrema: quizá lo hace para evitar la ronquera que lo ataca con suma facilidad. "Cualquiera que fuese la intención con que aquel varón lo ejecutara, ese hombre tenía una buena razón para hacerlo". ${ }^{19}$ Y después de todo, este es quizá el punto mas significativo, porque hacen falta razones para incurrir sistemáticamente en un acto que el medio no alienta porque valora su opuesto. Leer en silencio no es una anormalidad pero es todavía una anomalía.

La Edad Media aportó a la historia de la lectura, entre otras cosas, nuevas comunidades de lectores provistos de nuevas estrategias de lectura. Una de las más notables fue la comunidad monástica en la cual se refugió la cultura literaria desde el derrumbe del mundo romano. Es justamente en este ambiente donde la lectura vocalizada se vio acompañada por la lectura murmurante, en el marco de la lectio y la meditatio, que son las prácticas más características de la cultura monástica. De hecho, la lectio y la meditatio apuntan a dos tipos de tarea intelectual. La primera, la lectio, es una restauración cuidadosa y un análisis detallado del texto mediante los procedimientos de la gramática y la dialéctica; ella busca entrenar al ingenio natural a través del orden y del método de exposición y análisis. La lectio es la actividad característica del maestro que lee en voz alta a sus estudiantes, que responde a sus cuestiones y elucida los pasajes intrincados: en la tradición monástica ella incluye todas las disciplinas que se refieren a la página sagrada y al texto verdadero. ${ }^{20}$ Pero la lectio es sólo el antecedente de la meditatio, la cual está asociada a lo que la regla de san Benito llama lectio divina, una suerte de lectura subvocalizada. En efecto, una vez que está solo, el monje lee murmurando porque su propósito es digerir el texto, rumiarlo como hace una vaca con su alimento, para proveer a la memoria de los elementos indispensables para la meditación. Se lee porque es necesario nutrir pausadamente a la memoria con una serie de principios transcendentes y eternos que después serán vinculados, transpuestos, elaborados para penetrar mejor en el sentido del mensaje divino. La lectio divina no es propiamente el estudio sino una especie de síntesis entre el amor de las letras y el deseo de Dios, dice el diccionario patrístico. La lectio ofrece el texto segmentado en

\footnotetext{
${ }^{18}$ San Agustín, Las confesiones. Madrid, Sarpe, 1983, p. 132.

19 Idem.

${ }^{20} \mathrm{Cf}$. M. Carruthers, The Book of Memory. Cambridge, Cambridge University
} Press, 1993, pp. 156 y ss. 
fragmentos analíticos (cola), pero éstos deben ser almacenados de manera ordenada y dispuestos para su elaboración posterior (commata) a través de la meditación con el fin de interiorizarse en aquellas verdades que ya están alojadas en la memoria.

Esta concepción de la lectura sólo resulta comprensible teniendo como transfondo el papel que juegan la memoria y la reminiscencia en la práctica monástica. En efecto, la memoria es el depósito individual de las verdades contenidas en las escrituras; ella debe almacenar la presencia textual de Dios y ofrecer este material a la meditación cuyo objetivo respecto a las escrituras es elucidar la relación de Dios con cada una de las almas. Con ello, la exégesis monástica no busca instruir a la mente sino extraer desde el almacén de la memoria la presencia de Dios que en ella subyace. A este propósito -según J. Coleman- colabora la lectura subvocalizada:

[...] cuando el monje pronuncia el texto murmurando las palabras, él involucra más que su memoria visual de las palabras escritas: él involucra un proceso físico y muscular, mientras su memoria retiene la sensación de las palabras pronunciadas y otras. La meditación consiste en centrar su atención en ese ejercicio de memorización de tal modo que el texto se inscriba en el alma, un alma que se localiza en todas partes del cuerpo.

Sin embargo, esta memoria no es un simple catálogo de impresiones fijas; ella es más bien una memoria "asociativa" que impregnada con las palabras de la escritura es excitada por cualquier nueva alusión al verbo de Dios, de manera que se precipite espontáneamente una evocación de referencias completas a cualquier otra parte de las escrituras. Esta es la "productividad" intelectual del monje: la reminiscencia a través de la asociación fonética de una nueva serie de imágenes y palabras bíblicas. Por eso se ha insistido en que, con frecuencia, la composición del intelecto monástico no parece seguir un patrón lógico sino un plan psicológico de asociaciones verbales y aurales que configuran las disgresiones y los comentarios. A partir de esta "referencia" hecha por la memoria es imposible deducir si el monje está citando textualmente o está modificando. No se comporta pues como un "intelectual" sino como un "espiritual", por eso no hay ningún rastro de nuestra cultura textual, con sus citas, concordancias y referencias, que en todo caso aparecerá en la cultura escolástica posterior. En la cultura monástica, "el lenguaje fue utilizado para impulsar una asociación de experiencias más que para informar acerca de conocimientos".

Al interior de este universo intelectual, la lectura oralizada y la lectura subvocalizada forman un conjunto coherente: la voz es aún un complemento 
del texto exigido por la memorización. Aunque es próxima a la lectura silenciosa por el tono de la voz, la lectura subvocalizada es sin embargo lejana por las motivaciones que la animan: ella pertenece más a un mundo en el que la voz viva, como dictado o como murmullo, es aún un complemento obligatorio del texto. Las técnicas de lectura y escritura aún no permitían que se cumpliera la regla de silencio que san Benito había impuesto a la vida monacal. ${ }^{21}$ Para asegurar cierta privacía en la escritura y la lectura aún era preciso recluir a cada monje en el espacio reservado de la celda individual, "pero llene usted una sala de lectura con lectores medievales y el zumbido de murmullos y zuzurros sería intolerable". ${ }^{22}$

La voz no era sólo un acompañante del texto sino una parte de la producción del sentido: transcribir un texto a la voz humana, convertir en sonido los signos escritos era reencontrar el significado íntegro. La voz forma parte de la producción del significado y es el punto de partida y el punto de llegada del proceso. Este privilegio de la oralidad se percibe claramente al menos en dos cuestiones, esta vez referidas a la escritura: primero, porque hasta los siglos XI y XII, "componer" un texto, una obra, es sinónimo de "dictar". El autor medieval dicta su texto a uno o más escribas quienes toman "notas" sintéticas sobre tabletas de cera, las cuales son ampliadas para obtener el texto definitivo, cuya forma última no necesariamente estaba bajo el control del autor. El pasaje obligado por la oralidad impide aún otorgar a la noción de "composición" una asociación definitiva con el retiro personal y la interioridad. La iconografía hasta el siglo IX recoge este hecho al representar siempre a los evangelistas redactando sus textos bajo el dictado de un ángel o una paloma, o bien dictando ellos mismos a un escriba. ${ }^{23}$ En segundo lugar, incluso para el escriba solitario, la copia no es la transcripción silenciosa de un signo gráfico a otro signo gráfico sino el pasaje del signo a la voz y nuevamente al signo, tránsito en el cual se puede prestar más atención al oído. En efecto, tratando de explicar el error sistemático de un copista francés que en el manuscrito de La historia de Job cambia tres veces un "est" por un "et", el editor explica:

Creemos estar en presencia de un fenómeno que explicaría una gran cantidad de faltas "orales" en la copia de los manuscritos y que, desde el punto de vista psicológico es perfectamente explicable: el escriba, copiando, se pronunciaba a sí mismo las palabras y así, en cierto modo escribía como si alguien le dictara; en efecto, el veía "est", escuchaba el

21 Cf. P. Saenger, "Manières de lire médiévales", en H. J. Martin, Histoire de l'edition Francaise, vol. I. París, Promodis, 1984.

${ }^{22}$ H. J. Chaytor, From Script to Print. An Introduction to Medieval Vernacular Literature. Londres, Sidewick and Jackson, 1974, p. 22.

${ }^{23}$ Cf. P. Saenger, "Manières de lire médiévales", en op. cit., p. 135. 
sonido aproximado de la "e" cerrada, y escribía "et" puesto que en esa época tenían probablemente el mismo sonido. Tal hecho es aún más probable por el estado mismo del texto, porque la frase que copiaba era tan poco clara que un escriba que no tuviera bajo los ojos el original en latín, no vería quizá sino una serie de frases proposicionales, cada una de similar dimensión. ${ }^{24}$

No es pues sorprendente que en la manufactura de biblias de Tours, la más importante en el siglo IX europeo, se implantara un "control de calidad" REQ requisitum est que significaba "confrontado con el original". ${ }^{25}$

Fue justamente en el ámbito monástico donde, a partir del siglo VIII, habría de iniciarse la solución a las dificultades técnicas que obligaban a la oralización: la separación sistemática entre palabras y la división del texto en líneas constituidas por entre 10 y 15 letras. El inicio fue incierto:

[...] muy a menudo el escriba carolingio deja entre la última letra de la palabra y la primera de la siguiente un espacio un poco mayor que entre las letras inferiores de la palabra, pero casi con igual frecuencia este espacio no es más largo que entre cualquier par de letras y, a la inversa, no es raro encontrar entre dos letras de una palabra un espacio ligeramente más largo que de ordinario. ${ }^{26}$

Pero a pesar de estas vacilaciones, la importancia de esta modificación técnica fue enorme, porque al simplificar la lectura "liberó las facultades intelectuales del lector, permitiéndole leer cualquier texto en silencio y por tanto, con mayor rapidez intelectual". ${ }^{27}$

Pero si la remoción de esas dificultades técnicas era un paso necesario, no era un paso suficiente. Para transformar esa práctica de la lectura se requería de una alteración de tal magnitud que ese proceso sólo habría de comenzar a generalizarse unos cuatro siglos más tarde. La colaboración entre la vista y el oído, con la valoración de la oralidad, se prolongó varios siglos en los cuales definió prácticamente toda instancia de comunicación social. Lo indisociable de la vista y el oído es el rasgo más sobresaliente de este "modo de comunicación". Varios índices lo prueban. El primero es que los textos continuaron siendo el vehículo de la voz del ausente y siguieron "hablando" durante mucho tiempo.

${ }^{24}$ H. J. Chaytor, op. cit., p. 20.

25 D. Gauz, "Mass Production of Early Medieval Manuscrips: the Carolingian Bibles from Tours", en R. Gameson, ed., The Early Medieval Bible. Cambridge, Cambridge University Press, 1994 , p. 58.

${ }^{26}$ R. Marichal, op. cit., p. 237.

${ }^{27}$ P. Saenger, "Manières de lire médiévales", en op. cit., p. 297. 
Esta concepción que hace de la escritura el intermediario transitorio de la voz del ausente remonta por supuesto al mundo clásico. Así, al concluir una carta dirigida a Atticus, Séneca le pide: "escríbeme lo que se te venga a los labios" (in buccam...), en vez de "lo que se te venga a la cabeza" como quizá escribiríamos hoy. Incluso la reflexión personal la realiza en voz alta; lo único que impidió a Séneca exhortarse a sí mismo en un momento difícil fue una violenta crisis de asma. ${ }^{28}$ $\mathrm{Ni}$ siquiera el impulso aportado por el cristianismo hacia una mayor individuación de la lectura, con su exigencia de que cada uno leyera la palabra divina, alteró el privilegio otorgado a la oralización del texto: "en la primera iglesia, la sagrada inocencia que los cristianos de hoy adscriben a los niños del coro, descansaba en niños que leían en voz alta a un auditorio la palabra divina". ${ }^{29}$

La colaboración prevista entre el ojo y el oído determinaba naturalmente el tipo de literatura y de escrito que se producía. El redactor medieval contaba de antemano con ambos sentidos para la lectura y preveía su participación, por eso muchos documentos antiguos estaban preparados para ser vistos y oídos por aquéllos a quienes iban dirigidos: "numerosas cartas del siglo XII están dirigidas 'a todos aquellos que ven y oyen estas cartas en el presente y en el futuro' y con frecuencia se despiden con un 'valete' como si concluyeran una conversación con la audiencia”. ${ }^{30}$ Aún los monarcas bibliófilos, aquellos que poseían las bibliotecas más importantes de Europa, se hacían leer y no leían directamente ellos mismos. En el otro extremo social, los movimientos heréticos, a pesar de su insistencia en la fidelidad al texto y la obligación de cada uno a leer por sí mismo, debían recurrir a las recitaciones públicas ante grupos de iletrados deseosos de escuchar la palabra sagrada traducida a su propia lengua:

[...] los libros mismos se convirtieron en voces. Por donde quiera que existieron, ellos fueron oídos tanto como vistos, y las reberveraciones de los textos vocalizados resonaban en el exterior, con una exactitud y una inmediatez decreciente, lejos de los lectores y escuchas que trabajaban directamente sobre la página. ${ }^{31}$

Tales auditorios debían prestar una atención profunda a lo que escuchaban. Debe ser así, porque durante muchos siglos la expresión oral ha sido el único ingreso al discurso de la obligación y sólo a través de ella hombres y mujeres han

${ }^{28}$ Cf. G. Achard, La communication à Rome. París, Les belles lettres, 1991, p. 51.

${ }^{29}$ R. Lane Fox, "Literacy and power in early Christianity", en A. Bowman, ed., Literacy and Power in the Ancient World. Cambridge, Cambridge University Press, 1994, p. 144.

${ }^{30}$ M. T. Clanchy, From Memory to Written Record. Oxford, Blackwell, 1993, p. 253. 
podido recibir las directrices morales y sociales con las que orientan sus vidas. Pero la atención con que esos oyentes siguen el discurso oral difícilmente equivale a la actitud de recogimiento y diálogo consigo mismo del lector silencioso. No es una conjetura extravagante suponer que en muchos momentos ellos se comportaban del mismo modo que lo hacían los fieles de san Agustín:

[...] su participación era ruidosa; ellos aclamaban, aplaudían e interrumpían a su predicador y golpeaban violentamente su pecho, produciendo un gran rumor de palmadas cuando oían mencionar los pecados mortales, como el adulterio. También aplaudían, aprobaban o refutaban las citas que se hacían en un sermón. En Oea, los asistentes gritaron "falso" cuando la nueva Biblia de san Jerónimo describía a Jonás durmiendo bajo una hiedra y no bajo una calabacera (cosa que sabían por haberla visto representada en las primeras iglesias). ${ }^{32}$

La oralidad intrínseca del texto, lo mismo que modelaba el sermón o la prédica, modelaba la conducta del iletrado dándole una oportunidad de participar que después le sería retirada por la lectura y la escritura en silencio.

En el plano de la valoración social y de las actitudes, el término "acompañar" no refleja pues el papel que la voz ocupaba respecto al texto, porque la valoración profunda de la voluntad y de la experiencia humanas no recaían en el escrito sino en la expresión oral. Para que la voz y la memoria dejaran de ser la garantía de legitimidad del texto era preciso que éste se convirtiera en un objeto autónomo, susceptible de afirmar su propia validez. Pero esto requería de un largo proceso porque el mensaje inscrito en el corazón de los vivos tiene una significación particular, de manera que sólo los profundamente alfabetizados podían creer que la escritura era superior a cualquier objeto simbólico. Era normal que el texto no adquiriera de inmediato un valor indiscutible. Hacer del documento escrito la única verdad requirió de siglos de transformación de las convicciones humanas:

[...] en las raras instancias en las que el acuerdo parece depender sólo del documento, probablemente debemos asumir que éste está ocupando la antigua función de objeto simbólico, más que funcionando como un documento basado en su contenido escrito, a la manera alfabetizada moderna. $^{33}$

Sólo entonces cayeron en desuso esa serie de objetos rituales y se convirtie-

${ }^{31}$ H. Ashton, citado en W. Graham, op. cit., p. 39.

${ }^{32}$ Van Der Meer, citado en R. Lane Fox, op. cit., p. 145. 
ron en reliquias medievales, porque el lenguaje de la memoria que ellos expresaban ya no tenía significación para el mundo alfabetizado.

A la sucesión cronológica de las diversas prácticas de lectura debe sobreponerse entonces la serie de determinaciones funcionales que las validan o las aplazan. De este modo, la expansión de la lectura silenciosa que se constata a partir de la segunda mitad del siglo XIV es indicativa y sigue los ritmos de los factores que la exigen o la cancelan. Lo mismo que las demás estrategias de lectura, ella también pertenece a un mundo que sólo gradualmente pudo sustituir los valores en los que descansaba la lectura oralizada. Esta preeminencia es tanto la extensión de una innovación intelectual, como el signo de que la relación de un lector con su texto, con la comunidad de lectores y sus prácticas intelectuales, se estaban alterando. Mucho más allá del siglo XVI el libro siguió siendo lo que siempre había sido: "algo para leer en voz alta o recitarse, un aidemémoire y un repositorio de las palabras vocalizadas de un autor; en breve, un transmisor de la palabra cuya voz no puede contener y cuya palabra no es suficiente". ${ }^{34}$ Esta situación no habría de modificarse incluso con la aparición de la imprenta, la cual, si bien permitió la generalización de la lectura y aportó una profunda transformación en la tecnología de la comunicación y los hábitos intelectuales, en cambio no significó un desplazamiento inmediato de la comunicación oral. Los libros impresos no destruyeron de manera súbita el aprendizaje a través de la palabra y la acción; más bien en un primer momento ofrecieron nuevos elementos a la cultura oral, nuevas formas de relacionar sus valores con otras fuentes de autoridad, recientes y antiguas. ${ }^{35}$ Todavía una serie de escritos de los siglos XVII y XVIII muestran, tanto por las instrucciones que ofrecen al lector en voz alta, como por la estructura episódica de sus narraciones, que el autor estaba pensando en una serie de sesiones de lectura oralizada para la transmisión de su obra. La lectura privada y silenciosa y la lectura en voz alta se distribuyeron en diversas instancias y niveles sociales, en las casas de la nobleza, en las universidades, en la corte real o en los pequeños pueblos.

Sin embargo, subrayar la importancia otorgada a la lectura en voz alta o subvocalizada, la persistencia de las premisas en que las sustentan y de las expectativas que cumplen, no es contradictorio con el reconocimiento de la serie de factores que impulsaron a la lectura silenciosa y de la serie de consecuencias derivadas del encuentro entre escritura, lectura y silencio. La práctica de la lectura en silencio se ha hecho perfecta, pero esa perfección oculta el trabajo que se ha requerido para que el ojo humano se adapte a ese requeri-

${ }^{33}$ M. T. Clanchy, op. cit., p. 256.

${ }^{34}$ W. A. Graham, op. cit., p. 39.

35 Cf. T. Watt, Cheap Print and Popular Piety. Cambridge, University Press, 1994. 
miento y la serie de posibilidades que con ello se han abierto camino.

Primero, respecto a la velocidad de la lectura. Porque si los objetivos de la lectura en la antigüedad (la memorización, la expresividad, la lectura intensiva de pocos textos) no impulsan a aumentar la velocidad de la lectura, en cambio la multiplicación de textos y de géneros presiona en sentido contrario. La lectura silenciosa tiene la característica de ser mucho más rápida, sobre todo porque se hace independiente de los movimientos de la lengua y la vocalización y se concentra en el reconocimiento visual del contorno de las palabras y los signos gráficos. Desde la introducción de la separación entre palabras y los signos de puntuación se hizo posible un reconocimiento visual del texto, que podía ser retenido fácilmente por la vista, sin recurrir a la enunciación y a la memoria auditiva. Gracias a esa innovación se redujo la necesidad de recorrer varias veces con la vista los signos gráficos, guardando en la memoria las sílabas o palabras ya reconocidas hasta poder formar mentalmente la unidad con significado. Eso explica que en el mundo monástico, en el que la regla era que el monje recibiera un libro en préstamo por un año, se viera a un lector silencioso leer la Biblia en veinte días.

Por su velocidad, la lectura en silencio ha estado asociada (y recluida) a círculos de intensa vida intelectual:

[...] es posible e incluso probable que Aristóteles y sus discípulos leyeran gran parte de los materiales en los que basaban sus investigaciones rápidamente y en silencio, pero no debe olvidarse que cualquier texto que tuviera la menor pretensión literaria era escrito para ser leído en voz alta. ${ }^{36}$

Pero ésta no es la única razón. La lectura en silencio está asociada también a una actitud de reflexión y recogimiento particular: ella es una práctica cuya preferencia se detecta fácilmente en torno a la meditación, la reflexión y la interiorización. Por eso M. Capella afirma que los textos que deben ser aprendidos no deben leerse en voz alta sino que deben ser meditados con más utilidad en un murmullo y de preferencia de noche, cuando la memoria está más madura y no es interrumpida por los estímulos que provienen de otros sentidos. Aunque no son incompatibles con el murmullo, la meditación y la memoria son acompañantes del silencio; juntos configuran el estado de meditación atenta en que el entendimiento examina y retiene lo leído.

Es en este sentido que la lectura silenciosa refleja un cambio profundo cuya primera manifestación se encuentra en las prácticas intelectuales de los medios

${ }^{36}$ B. M. W. Knox, "Libros y lectores en el mundo griego", en Historia de la literatura clásica. Madrid, Gredos, 1990, p. 26. 
cultos. Por eso, seguimos creyendo correcto afirmar que ella recibió un impulso decisivo con la multiplicación de enunciados abstractos (llamémosles "analíticos"), que poseen un alto grado de complejidad, que exigen un esfuerzo intelectual considerable y que requieren del individuo una actitud reflexiva, lógica y consistente. Esta actitud del intelecto es imputable por completo a la estructura sintáctica y semántica de ese tipo de enunciados, porque en éstos predomina una síntesis analítica y una estructura intemporal de tipo lógico. La comprensión y el manejo de tales enunciados requiere de un tipo de conciencia que dialoga consigo misma y que piensa sobre las operaciones del pensamiento, es decir, que razona. Esta transformación no dejó, por supuesto, ningún rastro visible, pero su existencia puede postularse a través de una serie de fenómenos, el primero de los cuales fue la modificación en el material y la forma del códex sobre el que se realiza la lectura y la escritura. En efecto, la complejidad creciente de los argumentos que enfrentaba el pensador escolástico hizo que la tablilla de cera sobre la que se tomaban sus dictados, en la que sólo una parte de sus ideas podían estar a la vista, fuera sustituida por el cuaderno de hojas de pergamino el cual permitía la consulta de toda la composición, su revisión hacia atrás con el fin de asegurar la vinculación entre las premisas y las conclusiones, la concatenación lógica de los argumentos y el conjunto de referencias y citas auxiliares.

Desde el siglo IV el códex había sido preferido por los cristianos por la facilidad que aportaba en las referencias a las escrituras. Pero desde los manuscritos en cursiva gótica del siglo XV se desarrolla una actitud intelectual adicional: el hacer visibles las grandes articulaciones del discurso. Estos manuscritos venían a sustituir los textos de los siglos precedentes, con su bella página repleta de unciales, sus columnas de escritura compacta, sin divisiones, sin blancos, sin puntuaciones, con sus discretos inicios de frase; en síntesis, un bello manuscrito que no manifiesta en nada el orden del discurso:

[...] la lectura y hasta la búsqueda son fáciles, pero aparte de que los cortes son a menudo arbitrarios, todos los párrafos están en el mismo plano; la articulación lógica del pensamiento, la subordinación de las partes unas a otras no aparece por ningún lado [...] y con razón porque a veces esos textos no son sino una serie de noticias aisladas y en otros casos, preocupaciones literarias han conducido al autor a disimular, más que a acentuar, su plan. ${ }^{37}$

El texto escolástico por el contrario, se esfuerza en marcar las articulaciones que organizan lógicamente el discurso: "cada cuestión comienza con una mayúscula, a veces coloreada; cada división del texto tiene un signo específico y aunque no incluye títulos indicativos de parágrafos, se esfuerza por enunciar de entrada la cuestión a tratar". ${ }^{38}$ 
No es aventurado afirmar que esta reclusión de la conciencia ha contribuido a la configuración de nuestras nociones de lector y autor. Para el primero, en el momento en que la lectura dejó de ser una actividad colectiva, corporal y placentera, se dibujó un espacio diferente en el que se encontraba solo consigo mismo, en un diálogo interior. Por esta intensificación de la vida interior es difícil mantener una oposición entre lectura intensiva y lectura extensiva: en un sentido preciso, la necesidad de leer más textos no trajo consigo una menor, sino una mayor intensificación de la experiencia. El lector autónomo, que debía encontrar la motivación en sí mismo, había aparecido. Algo similar sucedió con el autor en el momento en que sustituyó el dictado a uno o más escribas por la composición hecha en soledad. Es cierto que contó, además, con la invención de la minúscula carolingia que le evitaba recurrir a los encombrosos artefactos del escriba, pero lo cierto es que al quedar solo, el autor quedó por completo responsabilizado de su texto. Saenger ha hecho notar que esta personalización del texto se refleja en el plano iconográfico después del siglo xII por el hecho de que los evangelistas o los autores son representados copiando un texto sostenido discretamente por un ángel, en un entorno en que el escritor está rodeado por estantes llenos de libros, obras de referencia y multitud de esbozos propios. Los autores de los siglos XIV y XV se consideraban ya compiladores y escribanos $\mathrm{y}$

[...] se enorgullecían de que sus escritos fueran nacidos directamente de su pluma. Por eso ellos mismos exigían al lector una nueva actitud y le ofrecían auxilios tales como enumerar sus argumentos y dividir lógicamente sus obras, permitiéndole orientarse en esa serie compleja de objeciones, respuestas y contraargumentos. El trabajo del autor tomó entonces una nueva dimensión, más individual y personal. ${ }^{39}$

Incluso los conjuntos de lectores silenciosos ofrecieron un aspecto nuevo: los estudiantes de París o Cambridge del siglo XIV podían compartir enormes salas amuebladas con estanterías, pupitres y bancos en los que cada uno se sienta al lado del otro sin (en principio) entorpecer su lectura y su concentración. En estas bibliotecas el silencio se convirtió en un imperativo: "los estatutos de la Sorbonne, establecidos hacia el final del siglo XV, pero que reflejaban prácticas anteriores, hacían de la biblioteca un lugar augusto y sagrado en el que debía reinar el silencio".$^{40}$ Estos lugares de lectura estaban, además, repletos de volúmenes de consulta y referencia de las mayores autoridades, que hubieran resultado inútiles al lector habituado a memorizar los pocos libros que leía entre

${ }^{37}$ R. Marichal, op. cit., p. 245.

${ }^{38} \mathrm{Idem}$. 
murmullos.

Naturalmente, esta nueva soledad de la lectura podía acarrear consecuencias diversas y hasta contrapuestas. Podía convertirse, como sucedió durante el siglo XVIII, en el acto por excelencia del fuero privado, en la parte más íntima de la vida interior sustraída al público, en un momento de intensa absorción afectiva, intelectual o espiritual. A esta conversión del libro en un compañero de la soledad se refiere R. Chartier cuando señala que "a la iconografía clásica, que hace de la biblioteca un símbolo de saber y de poder, se agrega la iconografía del acto de lectura mismo, que supone una relación íntima entre un lector y un libro". ${ }^{41}$ No es inusual entonces la representación iconográfica de lectores que en un retiro interior vuelcan todo su ser en la comprensión del libro. Pero esta nueva soledad del lector podía desembocar también en la lectura licenciosa que después del siglo XVI hizo revivir la literatura y las artes eróticas, el equivalente de nuestra pornografia, destinada a provocar en el lector una excitación profunda a través de la palabra y la imagen, que el mundo antiguo, más tolerante, hacía leer en voz alta. Es esta literatura la que habría de prolongarse a través "de esos libros que se leen con una sola mano" en los cuales los personajes se incitan mutuamente a ilícitas prácticas sexuales, excitados a veces por la lectura de otros libros. ${ }^{42}$ Finalmente, esa nueva soledad del lector también podía producir fines más elevados, promoviendo una nueva espiritualidad al ofrecer una nueva intimidad con los textos sagrados y permitir una experiencia más personal en la reflexión religiosa. Cada uno podía ahora meditar "con la mirada de la contemplación" los actos y las palabras de los seres divinos encontrando lo que había sido la aspiración de los grandes eruditos cristianos: una relación personal con lo divino. Pronto se percataron los guías espirituales que la lectura en silencio era una forma nueva de desarrollar la devoción y la espiritualidad ortodoxas: la lectura y la plegaria personales, apoyadas en la multiplicación de los llamados "libros de horas" medievales, que eran guías individuales de oración, impulsaron formas de interiorizar la fe y la convicción individual, y al alentar las dudas, pero también las respuestas, individualizaron el camino de la gracia. ${ }^{43}$

Lo que es seguro es que la lectura silenciosa contribuyó en alguna medida a alentar el escepticismo, que es en todo caso uno de los rasgos sobresalientes de la cultura moderna. Puesto que permite al lector entenderse con sus propios pensamienos, formular sus discrepancias sin temor a sufrir las represalias, con-

${ }^{39}$ P. Saenger, "Manières de lire médiévales", en op. cit., p. 64.

${ }^{40}$ Ibid., p. 137.

${ }^{41}$ R. Chartier, Libros, lecturas y lectores en la edad moderna. Madrid, Alianza Universidad, 1993, p. 160.

${ }^{42}$ R. Darnton, "Historia de la lectura", en P. Burke, ed., Formas de hacer historia. Madrid, Alianza Universidad, 1995, pp. 85 y ss. 
frontar al autor leído contra las reflexiones propias, la lectura y la escritura en silencio colaboraron quizá en forma minúscula con otros factores en esa "acumulación del escepticismo" de la que proviene una parte de la racionalidad moderna. No es sin duda debido al azar que la lectura silenciosa resulta contemporánea con las grandes herejías universitarias y laicas de los siglos XIII y XIV, que no sólo exigían una lectura interiorizada sino también una transmisión silenciosa de las ideas dentro y fuera de las salas de clase. ${ }^{44}$

La paulatina sustitución de la lectura en voz alta no fue únicamente el remplazo de una técnica de lectura por otra, sino una transmutación gradual de valores, ideales y objetivos. La lectura en voz alta representa, además de una forma de transmisión de saber, una manera de constituir y pertenecer a una comunidad de lectores, un recurso a las facultades de la memoria y del cuerpo, una valoración de la presencia y la voz humanas. La desaparición del espacio multicolor del lector y su auditorio y su sustitución por el lector autónomo, solitario y automotivado, que enfrenta un libro que es esencialmente un objeto visual, no podía dejar de ser resentida como una pérdida: la victoria de la mano, el ojo y la página sobre la voz, el oído y la retórica del mundo antiguo.

Una vez que la palabra ha sido transpuesta de la manera más artificial del dominio del oído al dominio del ojo lector, del dominio de la voz a la provincia de la mano escritora, ella se ha secado cada vez más y se ha marchitado: la palabra se ha retraído hacia sí misma y se ha convertido cada vez más en un enigma. ${ }^{45}$

Pero todo esto era inevitable, porque era el costo de llegar a un documento con páginas silenciosas.

${ }^{43} C f$. P. Saenger, "Prier de bouche et prier de coeur", en R. Chartier, op. cit., p. 207.

${ }^{44}$ Cf. P. Biller, ed., Heresy and Literacy 1000-1530. Cambridge, Cambridge University Press, 1994, pp. 19 y ss. 
${ }^{45}$ A. Miller, citado en W. Graham, op. cit., p. 44. 